Universidad de Guadalajara

Derecho Global. Estudios sobre Derecho y Justicia Año 2021, Vol. VI. Número 17, Marzo - Junio, pp 133-165, ISSN: 2448-5128 e-ISSN: 2448-5136

https://DOI.org/10.32870/dgedj.v6i17.313

CRISTINA I. CASTELLANO GONZÁLEZ Universidad de Guadalajara, México cristina.castellano@academicos.udg.mx

DAVID ISRAEL MARTÍNEZ RODRÍGUEZ

Universidad de Guadalajara, México davidisraelmr@gmail.com

\title{
LA CARAVANA MIGRANTE CENTROAMERICANA: POBREZA, VIOLENCIA Y MIEDO BAJO EL PRISMA DE LOS DERECHOS HUMANOS
}

\section{The CENTRAL AMERICAN CARAVAN: POVERTY, VIOLENCE AND FEAR, UNDER THE PRISM OF HUMAN RIGHTS}

Recibido: 11/12/2019 Aceptado: 08/05/2020 


\title{
RESUMEN
}

En este artículo, indagaremos algunas de las aristas que provocan el fenómeno migratorio de las caravanas migrantes centroamericanas. Iniciaremos con el tema de la pobreza entendida como incertidumbre económica radical, enseguida nos ocuparemos de la violencia y el miedo como factores determinables para impulsar la migración. Con el apoyo de una metodología reflexiva en donde se toma en cuenta la investigación en Derechos Humanos, articularemos un análisis sobre los vértices que conectan estas dos dimensiones para luego examinar las posibles contradicciones que encierran las caras del mundo fenoménico y el jurídico. Concluiremos con una puesta en perspectiva del debate existente sobre la ponderación de derechos, vinculado a temáticas de migración y derechos humanos.

\section{Palabras Clave:}

Migración, caravana migrante, derechos humanos.

\begin{abstract}
This article researches the migratory phenomenon of Central American migrant caravans. We will analyze the poverty understood as radical economic circumstance, then we will deal with violence and fear as determinable factors to boost migration. With the support of a reflexive methodology where Human Rights research is taken into account, we will articulate an analysis of the vertices that connect these two dimensions and then examine the possible contradictions that enclose the faces of the phenomenal and legal world. We will conclude with a perspective on the existing debate on the weighting of rights, linked to migration and human rights issues.
\end{abstract}

\section{KEY WORDS:}

Migrant caravan, human rights. 
Sumario: I. La caravana migrante. II. Extrema inCERTIDUmbre ECONÓMICA. III. VIOLENCIA Y MIEDO: LAS CONSTANTES EN ORIGEN, TRÁNSITO Y DESTINO DE LA CARAVANA MIGRANTE. IV. MigRACIÓN y Derechos Humanos en MéXico. 1. Concepto de derechos Humanos. 2. DeREcho humano a tRANSITAR LIBREMENTE Y COMO SE REGULA EN LA NORMATIVA MIGRATORIA MEXICANA V. Conclusiones. Bibliografía.

\section{LA CARAVANA MIGRANTE}

$\mathrm{L}$ a migración colectiva de viajeros centroamericanos pasando por México no se relevó a manera de trauma social por medio de la llamada "masacre de San Fernando" acontecida en 2010 en el estado de Tamaulipas en la que fueron víctimas casi doscientas personas que habían sido secuestradas y luego asesinadas masivamente por el crimen organizado; se suman numerosos episodios de personas en movilidad circulando en la llamada "Bestia", que es un tren de carga que va del sur al norte de México y del cual se sirven los viajeros para llegar a la frontera norte de México con los Estados Unidos; también se cuenta con la presencia de la Caravana de Madres de Migrantes Desaparecidos articulada en el Movimiento Migrante Mesoamericano cuya existencia remonta a más de quince años de búsqueda de familiares perdidos. ${ }^{1} \mathrm{~A}$ pesar de que, con estos tres ejemplos, se constata la existencia de migraciones colectivas centroamericanas desde antaño, no es sino hasta la segunda década del siglo XXI, con la llegada de una alternancia política de izquierda en México, que asistimos a la visibilidad de un fenómeno de migración masiva en caravana, mismo que se volvió un espectáculo popularizado y bautizado por los medios de comunicación como "caravana migrante".

En este artículo, indagaremos algunas de las aristas que provocan el fenómeno migratorio de las caravanas migrantes centroamericanas. Iniciaremos con el

\footnotetext{
${ }^{1}$ Sánchez Soler, Martha, Movimiento Migrante Mesoamericano. ¿Quiénes somos? Fecha de consulta: 09/ noviembre/2019 https://movimientomigrantemesoamericano.org/
} 
tema de la pobreza entendida como incertidumbre económica radical, enseguida nos ocuparemos de la violencia y el miedo como factores determinables para impulsar la migración. Con el apoyo de una metodología reflexiva en donde se toma en cuenta la investigación en Derechos Humanos, articularemos un análisis sobre los vértices que conectan estas dos dimensiones para luego examinar las posibles contradicciones que encierran las caras del mundo fenoménico y el jurídico. Concluiremos con una puesta en perspectiva del debate existente sobre la ponderación de derechos, vinculado a temáticas de migración y derechos humanos.

\section{EXTREMA INCERTIDUMBRE ECONÓMICA}

Una de las teorías que buscan explicar los fenómenos migratorios desde mediados del siglo XX es la expuesta por la escuela neoclásica ${ }^{2}$ que establece que el surgimiento de este tipo de fenómenos se debe a causas de naturaleza económica. Es por ello que esta teoría puede aplicarse en cierta medida para explicar y entender los motivos de los desplazamientos migratorios irregulares de Centroamérica, en especial los que provienen de los países que componen el Triángulo Norte de Centro (TNC), pues estos se caracterizan por una larga data de expulsión de migrantes irregulares que tuvieron su motivación para dejar sus lugares de residencia en la carencia de empleos, servicios públicos como el de seguridad, la salud, educación y básicamente los índices de pobreza en que vivían.

En términos generales, la estabilidad, el crecimiento y el desarrollo económico de los países se mide de acuerdo a su Producto Interno Bruto (PIB), el cual consiste en la suma de los bienes, servicios, transacciones comerciales y empleos que se producen en estos en un periodo de tiempo determinado, dato económico

\footnotetext{
${ }^{2}$ Para los neoclásicos, que son quienes han hecho mayor desarrollo empírico, en el origen de la emigración predominan las razones económicas por encima de otras razones. Sobre los efectos se viene promoviendo el análisis micro territorial debido a que no existe una distribución aleatoria de la migración, sino que se concentra en mayor proporción en las zonas de mayor crecimiento económico dentro del país de destino. (Gómez, 2010: 84)
} 
cuantitativo que en los países del TNC observa el siguiente comportamiento:En los últimos diez años, las economías de El Salvador, Guatemala y Honduras han crecido a una tasa promedio de $1.8,3.6$ y 4.1 por ciento, respectivamente, pasando de representar USD 48.4 millardos a USD 96.5 millardos. No obstante, este crecimiento se ha concentrado en sectores económicos relacionados con servicios, los cuales absorben muy pocos empleos y, en muchos casos, están insertos dentro de regímenes tributarios que disminuyen o anulan su responsabilidad impositiva. (Instituto Centroamericano de Estudios Fiscales, 2015: 02)

De acuerdo con este dato, aunque el mercado de los servicios mantiene un crecimiento considerable dentro de los países que integran el TNC, el sector de la población que los generan se ven beneficiados a través de estrategias fiscales amparadas por formas legales y jurídicas que tienen como objetivo pagar lo mínimo o no pagar tributos a los gobiernos de estos países, razón que nos lleva a concluir que este supuesto crecimiento económico no impacta al grueso de la población centroamericana ya que no son una fuente de generación de empleo ni aportan al desarrollo económico del país en el que se generan. Además: La región se caracteriza por sus altos niveles de pobreza, que alcanza cifras de 47\% (pobreza general) y $18,6 \%$ (pobreza extrema), donde tenemos países como Honduras con uno de los índices de pobreza más altos de América Latina $(66,2 \%)$ y Guatemala, con un índice alto también de 53.71\%. Pero existen en la región países con índices de pobreza muchos menores como Costa Rica y Panamá, con 21,7\% y $25,8 \%$ respectivamente. En el medio se encuentran El Salvador y Nicaragua con porcentajes de 43.5\% y 44.7\%, respectivamente. (Grau Crespo, 2013: 07)

Es por ello que la teoría de la escuela neoclásica puede aplicarse para explicar los motivos de la migración irregular centroamericana, pues está se motiva por los siguientes factores económicos que afectan a una gran parte de la población de los países que componen el TNC. El primer factor económico que podemos identificar es la poca oferta de trabajo sumada a su alta demanda (que desde un punto de vista económico se puede entender como la carencia de oportunidades) que genera un impacto negativo para los individuos y sus familias dando como resultado la imposibilidad material de proveer y cubrir necesidades básicas como la alimentación, renta, salud y educación. Esta situación al ser compartida de 
manera constante en múltiples hogares en la región del TNC altera la proyección local de la vida, el arraigo territorial de las personas y genera deseos de movilidad que no son sino migraciones económicas forzadas. ${ }^{3}$

Tampoco debe perderse de vista la proliferación de bandas criminales como las maras o los grupos de narcotraficantes que operan en esta región, ya que por medio de la comisión de sus actividades delictivas imposibilitan el desarrollo económico en la región, lo cual se puede identificar como segundo factor económico que motiva la migración irregular centroamericana, pues los altos índices en las tasas de delitos como robos, violaciones, homicidios y extorciones como el cobro de cuotas (cobro de piso) a quienes cuenten con algún negocio comercial a cambio de brindarles una supuesta protección, hace insostenible la capacidad de los comerciantes que cuentan con pequeñas y medianas empresas o negocios familiares para el sostenimiento de estos, y en consecuencia para procurarse su sustento, pues en caso de negarse a pagar dichas cuotas se ven en riesgo de sufrir agresiones físicas en su persona, sus familias, sus locales comerciales e incluso la posibilidad de perder la vida.

De la mano con lo anterior se presenta el tercer factor económico que propicia la migración irregular, siendo este la falta de confianza para la inversión económica interna en los países del TNC, pues esta se ve propiciada por la falta de un auténtico estado de derecho en el que se garantice la seguridad pública, lo cual se observa en el libre actuar de los grupos criminales ya mencionados.En esos lugares de salida se reporta una creciente delincuencia de las maras: cobro de cuotas de seguridad, derecho de piso, ajustes de cuentas, robos indiscriminados, lo cual se une a gobiernos sumidos en la corrupción, la violencia y la incapacidad de ofrecer garantías mínimas de mejora a la población más pobre y vulnerable. (Vega, 2018: 209)

De acuerdo con Briceño-León (2007) citado por Jiménez (2016), la población de esta región percibe un alto índice de impunidad, pues las instituciones administrativas

\footnotetext{
${ }^{3}$ El Glosario sobre Migración de la Organización Internacional para las Migraciones (OIM) distingue diversos tipos de migración cuyos matices y fronteras conceptuales se delimitan de manera porosa. Véanse por ejemplo los de conceptos de migración internacional, migración masiva, migración espontánea y migración económica. (OIM, 2006: 39-41).
} 
y policiacas encargadas de la investigación y persecución de los delitos, así como los aparatos judiciales reciben sobornos de parte de las organizaciones criminales a cambio de que se les permita para operar libremente: La violencia generada por el mercado de la droga tiene altas cuotas de impunidad. Existe la percepción bastante generalizada de que quien comete delitos en este campo difícilmente irá a prisión. Las ganancias del mercado de la droga son astronómicas y ha conducido a la corrupción de policías, fiscales y jueces con lo cual causa un gran daño en las instituciones que han de velar por la justicia. (177)

El estado de derecho se vuelve nugatorio, es decir, norma vigente no aplicable y que deja en la población un sentido de decepción hacia sus autoridades políticas, incertidumbre y un temor, pues quienes se supone se encuentran en esos cargos para brindarles los servicios de seguridad pública e impartición de justicia no son otra cosa que mercenarios que se venden a los intereses de las bandas criminales, que bajo tal tesitura resulta impensable que pequeñas empresas como negocios familiares si quiera puedan realizar actividades ante el libre actuar de las bandas criminales.

El cuarto factor económico es la brecha social que impacta en la educación de la juventud en los países del TNC, pues por un lado tenemos a los hijos de las personas que cuentan con capital económico, quienes pueden aspirar a superarse a través de una educación universitaria y acomodarse en los sectores económicos de producción, lo cual no es opción en muchos casos para adolescentes y niños de familias de escasos recursos económicos, pues al no contar con recursos ni capitales se enfrentaran a la dificultad de poder cursar y costearse los gastos que impliquen su educación en cualquier nivel escolar, ya que la norma es sobrevivir en una sociedad que no ofrece oportunidades de trabajo. Nos encontramos así, frente a condiciones de pobreza y desigualdad que afectan terriblemente el conjunto social, impactando de manera grave a la juventud y la niñez, sectores de la población que no se deben pasar por alto dada su especial condición de vulnerabilidad.La UNICEF señala que en El Salvador, 8 de cada 10 niñas y niños viven en pobreza, mientras casi la mitad sobrevive en situación de pobreza extrema. Además, se calcula que 140,700 niños, niñas y adolescentes se encuentran en situación de trabajo infantil y 17,512 fueron migrantes no acompañados en el 2016. El Salvador es el país del mundo con mayor tasa de homicidios de niñas, 
niños y adolescentes. (Centro de Estudios de Guatemala, 2018: 12)

Por lo tanto, las condiciones de desigualdad social en esta región debe generarnos las siguientes interrogantes: ¿Qué profesión, trabajo u oficio pueden vislumbrar los jóvenes centroamericanos? ¿Qué futuro aguarda a una niñez que se ve expuesta a situaciones de alta competitividad en mercados laborales con bajos beneficios? ¿Qué pueden esperar las nuevas generaciones si la educación no es una garantía para figurarse un porvenir? ¿Cómo buscar dignidad y cómo sobrevivir en tales condiciones? Sobre todo cuando:

[...] en América Latina son los jóvenes quienes encabezan las estadísticas del delito y particularmente de los crímenes violentos. Hablemos de Venezuela, Colombia, Brasil o Centroamérica, los países de la región comparten la alarmante tendencia de una juventud cada vez más involucrada en actividades criminales. El auge del narcotráfico y la delincuencia organizada como actores que le disputan territorialidad y legitimidad a los Estados no es un fenómeno privativo de México. (Centro de Estudios Sociales y de Opinión Pública, 2015: 02)

El panorama no es alentador, pues de acuerdo con la información brindada por el documento anteriormente citado, una gran parte de los niños y los adolescentes en la región del TNC se encuentran ante una complicada disyuntiva, pues por un lado carecen de oferta de medios educativos y laborales que les permitan superarse, hacerse de una profesión u oficio que les permita subsistir a futuro, aunado a condiciones de violencia donde grupos criminales como narcotraficantes y pandillas además de reclutarlos de manera forzada, se vuelven una peligrosa opción para hacerse de un ingreso por el cual poder mantenerse, pues con el objetivo de mitigar las carencias y la falta de oportunidades, la delincuencia organizada se vuelve atractiva para la juventud de los países de esta región a menos que opten por dejar sus hogares y buscar mejores oportunidades en otro país, sumándose con ello al fenómeno de la migración irregular. Además:

La violencia continúa siendo un obstáculo al desarrollo en la región, y el Triángulo Norte concentra las mayores tasas de violencia de Centroamérica y de América Latina, siendo particularmente elevada en Honduras. En 2012, la tasa de homicidios por cada 100,000 habitantes fue 90 en Honduras, mientras que en Guatemala alcanzó 34 y en El Salvador 41, superiores al promedio regional de 25. En 2013, se registraron 14,300 homicidios, de los cuales más 
del 90 por ciento se localizaron en los municipios con mayor emigración. En Guatemala, por ejemplo, la tasa de jóvenes, entre 18 y 21 años, que murieron por violencia alcanzó, en 2012, 55 por cada 100,000 habitantes comprendidos en ese grupo etario, casi duplicando la ya alarmante tasa de homicidios total. (Instituto Centroamericano de Estudios Fiscales, 2015: 04)

La investigación realizada por el Centro de Estudios y de Opinión Pública nos muestra como los indicies de violencia en la región de los países que conforman el TNC a la par de que van en incremento, también se han vuelto un ciclo dentro de las sociedades de estos países, en la que una cada vez más gran parte de sus adolescentes y niños pasan a engrosar las filas de las bandas criminales que operan en esta región, siendo partícipes activos en la comisión de delitos, proyección que queda respaldada con los datos proporcionados por el informe del Instituto Centroamericano de Estudios Fiscales.

Los diferentes factores económicos expuestos reflejan una terrible realidad a la que gran parte de la población que reside en la región del TNC debe hacer frente y dar respuesta de alguna manera, y la cual puede traducirse en opciones que van desde permanecer en la misma y soportar extorciones, impunidad y violencia generados por los grupos criminales al amparo de las autoridades, unirse a estos grupos y perpetuar el ciclo de violencia que impera en la región, o finalmente, decidirse por dejar sus lugares de residencia y emprender un viaje a otro lugar que prometa mejores oportunidades de desarrollo y sumarse de así a la data de tránsitos migratorios irregulares centroamericanos.

\section{VIOLENCIA Y MIEDO: LAS CONSTANTES EN ORIGEN, TRÁNSITO Y DESTINO DE LA CARAVANA MIGRANTE}

La violencia juega un papel crucial en los desplazamientos irregulares de personas y el caso de la caravana migrante centroamericana no será la excepción. Si bien la historia de muchos de los países centroamericanos se encuentra revestida de una larga serie de actos violentos como golpes de estado, revoluciones, levantamientos armados que buscan deponer un gobernante por otro, se han vuelto una serie 
de factores que provoca la ingobernabilidad en la región, sumando el hecho de que las autoridades administrativas de los diferentes países que conforman el TNC se han visto rebasadas para garantizar la seguridad pública de la población, viéndose superadas por los actos violentos de diversos actores delictivos, lo cual ha propiciado el surgimiento de grupos criminales como narcotraficantes y las maras que actúan ante estas omisiones por parte de los gobiernos de los países de esta región para hacerles frente, afectando de manera obscena el tejido social. Para los centroamericanos, los riesgos en su proceso migratorio hacia Estados Unidos se presentan desde el lugar de origen, donde también están expuestos a amenazas locales. La mayor preocupación, es el incremento alarmante de la intensidad de peligros a los que se enfrentan en su tránsito por México. La probabilidad de ser vulnerado es muy alta, pues la capacidad de evadir, resistir o enfrentar las agresiones y superar los posibles daños, es muy limitada. (Rodríguez, 2014: 22)

Según el Alto Comisionado de las Naciones Unidas para los Refugiados: "En el Triángulo Norte de Centroamérica se sufre altos niveles de violencia provenientes de grupos delictivos organizados, incluyendo un aumento sin precedentes en los índices de homicidios, violencia sexual, desapariciones, reclutamiento forzado en las pandillas armadas y extorsión.” (2017: 01). Lo más lamentable es el viciado ethos político de muchos de los gobernantes que buscan formas de mantenerse en el poder pasando la eficacia de sus gobiernos en materia de seguridad a segundo plano, lo cual deriva en la falta de un auténtico estado de derecho para los ciudadanos hondureños, guatemaltecos y salvadoreños que a su vez los deja exentos de contar con una seguridad pública, que al no permitir que se genere la confianza para que exista inversión, generación de empleos y comercio, los expone a condiciones que lejos de permitirles tener una vida digna y anhelada, les orilla a sobrevivir, a mantenerse con vida con el temor fundado ante el probable acontecimiento de un grave perjuicio, en resumen: se vive con miedo. Hablamos entonces de una descomposición social multilateral que conlleva a la gestación y proliferación de un estado de excepción en donde los únicos que operan con libertad son los grupos delictivos organizados: Aunque oficialmente no están en guerra, los países del TNCA experimentan una violencia como si estuvieran en un país en guerra o peor. Asesinatos, secuestros, extorsiones, violencia sexual son cotidianos y se ejecutan en la mayor impunidad. 
El crimen organizado, mediante bandas criminales asegura la violencia en tanto los gobiernos se ven imposibilitados de asegurar la seguridad ciudadana. (Centro de Estudios de Guatemala, 2018: 14)

La migración internacional irregular se vuelve entonces la opción que toman cientos de personas pertenecientes a los países del TNC para huir de la violencia, de la pobreza, del miedo, huir al fin de un estado de distopía constante. Una vez que los migrantes irregulares centroamericanos dejan sus lugares de residencia y dan inicio a su trayecto migratorio, los riesgos y el miedo no se quedan atrás, sino que por el contrario se vuelven constantes, que más que acompañarlos los asecharán a lo largo de su travesía. Los riesgos podrán clasificarse de dos formas: Generales, que consistirán en amenazas para todos los migrantes irregulares como grupo colectivo; mientras que la segunda clase de riesgos serán Específicos es decir, amenazas para ciertos individuos dependiendo de su sexo, género o preferencia, edad, nacionalidad e inclusive su idioma.

El tránsito que los migrantes irregulares centroamericanos realizan para llegar a la frontera sur de México no es tan complejo, pues varios de estos países cuentan con acuerdos internacionales que permiten la libre circulación de sus ciudadanos facilitando con ello el desplazamiento de estos en la región:Los países centroamericanos de Nicaragua, Honduras, el Salvador y Guatemala tienen una libre circulación de personas gracias a una serie de negociaciones, protocolos, leyes y reglamentos promovidos por el Sistema de Integración Centroamericana (SICA) que condujeron, en otros, al Acuerdo de Managua (CA-4), elaborado en 1993. (Vega, 2018: 21)

Las verdaderas dificultades del trayecto de los migrantes irregulares centroamericanos inicia con su llegada a la frontera sur de México, pues a diferencia de Nicaragua, Honduras, El Salvador y Guatemala que permiten la libre circulación de sus ciudadanos, México además de solicitar el pasaporte correspondiente, solicita adicionalmente a los ciudadanos de estos países la visa ${ }^{4}$ (documento por medio del cual se otorga una autorización condicionada de un

\footnotetext{
${ }^{4}$ Información que puede ser consultada en el sitio web del Instituto Nacional de Migración, Países y regiones que requieren visa para viajar a México, https://www.inm.gob.mx/gobmx/word/index.php/paises-requierenvisa-para-mexico/. Fecha de Consulta: 02 de Agosto de 2020 (Instituto Nacional de de Migración, 2019).
} 
país a un ciudadano extranjero, para entrar y permanecer temporalmente en dicho país, o para abandonarlo), por lo que el primer obstáculo que deben sortear los migrantes irregulares es el ingreso a territorio mexicano, teniendo que sortear o evadir a las autoridades migratorias como el personal del Instituto Nacional de Migración y a los miembros de la Guardia Nacional.

En junio de 2019, la Secretaría de Relaciones Exteriores comunicó que derivado de las negociaciones con autoridades estadounidenses en relación con la imposición de aranceles a productos mexicanos, 44 se acordaron acciones de control migratorio en México, incluyendo el despliegue de 6 mil elementos de la Guardia Nacional para que realizaran acciones de control migratorio. Los intensos flujos migratorios de las caravanas trajeron importantes desafíos para la atención de las personas migrantes, en primera instancia, brindarles ayuda humanitaria, y debida asistencia a grupos vulnerables, así como atender a aquellos que solicitaban la protección internacional de México y, con ello, garantizar una estancia digna en recintos migratorios, aunado a mantener una buena relación diplomática y comercial entre el Estado mexicano y el estadounidense. (CNDH, 2019: 75 y 76)

En caso de que los migrantes irregulares puedan evadir a las autoridades migratorias antes mencionadas, estos se encuentran ante una nueva disyuntiva, pues deben decidir por alguna de las rutas terrestres que los lleven hasta la frontera de México con los Estados Unidos de América: "Los flujos centroamericanos, en particular, ingresan a México principalmente por un sinnúmero de caminos vecinales localizados en los estados de Chiapas y Tabasco." (Casillas, 2008: 161), pudiendo optar por las rutas de la costa del pacifico, del Golfo o seguir por una parte más central con dirección a la capital de la república mexicana: Históricamente, la frontera de Chiapas ha sido la puerta de entrada y el punto de partida de la ruta de tránsito hacia el norte de México. La ruta tradicional que, desde la década de los ochenta y hasta el año 2000, seguían los migrantes centroamericanos iniciaba en el área de Tecún Umán-Suchiate (ruta de la costa), o en el área de El Carmen-La Mesilla (ruta de la panamericana). (Martínez, Cobo, \& Narváez, 2015: 134)

Una vez que los migrantes irregulares se encuentran transitando por territorio 
mexicano, su misma condición de irregularidad los orilla a tratar de pasar lo más desapercibidos posibles dentro la sociedad, situación que los deja en un gran estado de vulnerabilidad al ser el blanco de discriminación y agresiones físicas y verbales de la misma sociedad mexicana, grupos policiacos que buscan extorsionarlos.

Independientemente de la ruta elegida por los migrantes irregulares, una difícil realidad a la que habrán de hacer frente es que a medida que se vayan internando más y más a territorio mexicano, su misma condición de irregularidad los orilla a tratar de pasar lo más desapercibidos posibles dentro la sociedad, situación que no hace más que acentuar el gran estado de vulnerabilidad: "La vulnerabilidad surge de factores físicos, sociales, económicos y ambientales que varían considerablemente en el trascurso del tiempo. Algunos factores de vulnerabilidad de los migrantes tienen que ver, por ejemplo, con la discriminación o la marginalidad socioeconómica, [...]" (París, Ley \& Peña 2016: 03), situación que los hace blanco de discriminación y agresiones físicas y verbales de la misma sociedad mexicana, grupos policiacos que buscan extorsionarlos: Actualmente, la relación entre el migrante centroamericano y el Estado mexicano -sociedad y gobierno- se enmarca en un doble telón. Primero, la versión oficial dada por el gobierno a través de su política migratoria, así como lo establecido en los tratados firmados y ratificados por México en materia de migración y derechos humanos; y por otro lado, las investigaciones y recomendaciones hechas por medios de comunicación, Organizaciones No Gubernamentales (ONG's), la Comisión Nacional de los Derechos Humanos (CNDH), entre otros organismos nacionales e internacionales que velan por la protección de los derechos humanos, y denuncian maltratos y violaciones a las personas: desde discriminación hasta violencia física, pasando por la exclusión social que impide una integración homogénea de las sociedades. (Fuentes \& Ortiz, 2012: 160)

Este factor de vulnerabilidad como riesgo general para los migrantes irregulares centroamericanos propicia la aparición de un tercer actor que ve en estos objetos potenciales para el desarrollo de sus actividades; el crimen organizado. Las bandas criminales y grupos de narcotraficantes ven a estos como blancos potenciales para el desarrollo de sus actividades delictivas, así como en el cobro de piso para otros delincuentes que dependen de los migrantes irregulares 
principalmente para mantenerse de sus actividades ilícitas como los traficantes de personas o mejor conocidos como 'polleros':Al traslaparse las rutas del tráfico de personas con las del narcotráfico, las mismas organizaciones criminales se encargan de "regular" el tránsito de los migrantes centroamericanos. Obligan a los traficantes de personas a pagarles fuertes sumas de dinero, les imponen tanto la frecuencia y la ruta como el número de migrantes que pueden viajar en el grupo. (París, Ley \& Peña, 2016: 23)

Para desgracia de los migrantes irregulares, las rutas que estos toman para llegar a la frontera norte mexicana coinciden con las rutas de algunos de los carteles de tráfico ilegal de drogas a los Estados Unidos de América, por lo que algunos de estos carteles reclutan, emplean o secuestran a migrantes irregulares para que coadyuven en sus operaciones ilícitas. Cabe destacar que estos grupos criminales hacen honor a la denominación de crimen organizado, pues tienen bien identificados a los migrantes irregulares ${ }^{5}$, al grado de conocer su llegada, movimientos que realizan, así como el número de estos, además de recurrir a homicidios y desapariciones en masa de migrantes una vez que no les son de utilidad o si es que se niegan a trabajar para estos, recuérdese el terrible antecedente del Municipio de San Fernando, en el estado de Tamaulipas. ${ }^{6}$ La delincuencia organizada ha analizado a los migrantes en tránsito: sus movimientos, cómo se agrupan, a dónde llegan y cómo se trasladan. Incluso los han infiltrado, lo cual facilita su secuestro y extorsión. En esta cadena delictiva, también participan centroamericanos, sea por coerción, por convencimiento o porque ya participaban

\footnotetext{
${ }^{5}$ Las rutas de tránsito resultan particularmente difíciles para las mujeres, por los recurrentes asaltos acompañados por violaciones y otros abusos sexuales, un hecho que se halla bien documentado. Por ejemplo, Óscar Castro Soto (2010) señala que los secuestradores investigan a los grupos de migrantes con anticipación y buscan aquéllos en donde viajan mujeres para secuestrarlas. (Willers, 2016: 176).

${ }^{6}$ En años recientes, la violencia hacia los migrantes en tránsito por México hacia Estados Unidos ha alcanzado niveles inéditos; el secuestro y el asesinato han sido la expresión máxima de esa violencia, pero no la única. Por otra parte, hay evidencias suficientes para afirmar que los eslabones delictivos de México se han extendido y conectado con otros grupos ya existentes en algunas localidades centroamericanas y estadounidenses, afectando tanto a migrantes centroamericanos y de otras nacionalidades en tránsito internacional, como a migrantes mexicanos. La masacre de 72 migrantes — en su mayoría centroamericanos - en San Fernando, Tamaulipas, en agosto de 2010, y el descubrimiento de otras fosas con más migrantes, incluidos mexicanos, entre 2011 y 2012, permite señalar que se está viviendo una especie de "tsunami” de violencia que arrastra a los migrantes. (Rodríguez, 2014: 19).
} 
en actividades delictivas [...] Estos grupos delictivos también extorsionan a los traficantes de personas o les recaban un pago. Les cobran por dejarlos pasar con los migrantes, so pena de secuestro o ejecución de los propios migrantes. Ante la fuerza de grupos como los Zetas, los guías y "coyotes" han cedido y acordado el monto del pago. En los casos de organizaciones más sofisticadas de traficantes de personas, se han establecido convenios cupulares. (Rodríguez, 2014: 20 y 21)

Debe reconocerse entonces que la composición de los migrantes irregulares es heterogénea, es decir, se trata de un grupo compuesto por varios grupos, los que a medida que se van clasificando e individualizando, podemos observar que el drama humano que se vive en el trayecto de estos, en realidad son una serie de dramas, y que tal y como se mencionó con anterioridad, habrá ciertos factores que harán más vulnerables a ciertos individuos dentro de un ya de por si grupo vulnerable. Se debe reconocer entones la existencia de ciertas circunstancias de riesgo que solo afectan a unos cuantos, pues no son los mismos riesgos los que afrontan los varones o masculinos, las mujeres o las féminas, los homosexuales, lesbianas y transexuales, los ancianos, adultos, adolecentes, niños y niñas o aquellos migrantes irregulares que no sean oriundos de los países centroamericanos, como haitianos, africanos o asiáticos, estos últimos que tendrán los problemas del lenguaje, que México y Centroamérica comparten, y que de cierto modo facilitan su comunicación durante su trayecto migratorio por territorio mexicano, y que incluso puede ayudarlos al tratar de mimetizarse con la sociedad mexicana. Las diferencias de género son también notables en los riesgos que los migrantes refieren a través de la EMIF Sur. Las mujeres dicen con mayor frecuencia haber enfrentado algún riesgo $(16,6 \%)$ que los hombres $(15,4 \%)$, pero los riesgos percibidos no son los mismos. (París, Ley, \& Peña, 2016: 24)

Durante su trayecto de migración irregular por el territorio de la república mexicana, el sexo o el género de los migrantes se vuelve una condición que hace de estos vulnerables a riesgos específicos, en especial a las mujeres sin importar su edad, pues además de correr los riesgos generales ya mencionados, resultan ser el objetivo de grupos delictivos que se dedican a la trata de personas o proxenetas que viendo la necesidad en la que se encuentran, por medio de engaños de falsos trabajos o recurriendo directamente al secuestro, obligando a sus víctimas a 
prostituirse, ser objeto en la trata de personas y en el caso de las niñas y niños los venden en redes de pederastas: "En Tapachula se asientan también grupos de delincuentes dedicados a la trata de personas, especialmente de mujeres a las que les ofrecen "trabajo" de meseras en restaurantes y que acaba en prostitución forzada. (Vega, 2018: 210); situación de riesgo que no es muy diferente a la que viven los migrantes irregulares que pertenecen a la comunidad LGBTTTIQ (por sus siglas: Lesbiana, Gay, Bisexual, Transgénero, Travesti, Transexual, Intersexual y Queer), que al igual que las mujeres corren el riesgo de sufrir el mismo destino de prostitución:El trabajo sexual, especialmente en la calle y sobre todo cuando se trata de adolescentes LGTBI, conlleva altos riesgos de seguridad física, de violencia y de problemas de salud. Hay también un riesgo agravado de explotación sexual y trata con fines de explotación sexual. (Morondo \& Blanco, 2018: 21)

Todo lo anterior no hace más que evidenciar una grave crisis que han sufrido, sufren y sufrirán cientos de miles de personas que ingresen a territorio mexicano de manera irregular por su frontera sur; crisis en la cual se ven afectados su dignidad y derechos humanos, por lo cual es urgente emprender trabajos atiendan las causas que originan la migración irregular, así como la aplicación de programas que entiendan la composición de los flujos migratorios.

[...] la migración de tránsito por México, a pesar de que el gobierno mexicano lo niegue en los diversos foros, es realmente de crisis humanitaria, porque se da en un contexto de catástrofe donde intervienen factores naturales y de conflictividad social que operan sobre la vulnerabilidad con que salen de sus países de origen y la vulneración que va operando conforme se adentran en el territorio mexicano, con lo cual se limita o impide la capacidad de aplicar estrategias eficaces que permitan lograr el objetivo de la jornada migratoria: Llegar a los Estados Unidos. (Vega, 2018: 21)

\section{Migración y Derechos Humanos en MéXico}

Desde el año 2018, la caravana migrante centroamericana en su paso por México, colocó en el centro de la atención mediática el encuentro de tres actores colectivos: el primer actor fue propiamente la caravana migrante, observada en conjunto como 
si se tratara de un ente masivo homogéneo compuesto por personas viajando de manera irregular pero siempre identificables. El segundo actor involucrado fueron las personas que conforman las instituciones gubernamentales pertenecientes al país de tránsito, entidades federativas, estatales y municipales, organismos encargados de guardar y restablecer el orden, también aquellas competentes en materia de tránsito de personas, así como los tribunales y juzgados en los casos en que se ameritara una solución jurisdiccional: funcionarios públicos en el ejercicio de sus funciones. El último actor colectivo fue la población nativa del país al que llegó la caravana migrante, es decir, la sociedad civil mexicana que mostró, por medio de las redes sociales, una de las caras más amargas y desconocidas de la xenofobia mexicana.

La intensa interacción entre los tres actores colectivos puso a prueba las estructuras jurídicas, políticas e ideológicas de México y su relación tanto con los vecinos centroamericanos como con el resto del mundo observante. Efectivamente, durante varias semanas, las autoridades mexicanas competentes estuvieron bajo del ojo escrutador de los medios informativos y de una opinión pública muy dividida con respecto a dicha problemática. Lo que se puso a prueba fue la estructura jurídico/política en el tratamiento y actuación de Derechos Humanos que brindaron a las personas centroamericanas en tránsito. La Presidencia de la República, la Secretaría de Gobernación (SEGOB), la Secretaría de Relaciones Exteriores (SER), el Instituto Nacional de Migración (INM), la Policía Federal Preventiva (PFP) y posteriormente la Guardia Nacional (GN), autoridades, juzgados y tribunales fueron desafiados por los desplazamientos continuos y numerosos de los migrantes.

En cuanto a la estructura ideológica, los detractores de la caravana migrante diluyeron la idea de una cierta "hermandad latinoamericana" incondicional. Al contrario, lo que se detonó fue el miedo recíproco en el momento en que las autoridades tuvieron que poner en práctica la normativa aplicable y el trato jurídico estipulado que debía brindarse a las personas migrantes. En suma, la interacción de las autoridades y de los integrantes de la caravana migrante obliga a tener dos perspectivas; por un lado tenemos los requisitos impuestos por el estado mexicano que todo extranjero deberá reunir para ingresar al territorio, y por el otro la situación particular de la caravana migrante, en relación con 
los Derechos Humanos como normas vigentes dentro del sistema constitucional mexicano. Por lo tanto, la coerción que produce el fenómeno de migración irregular de la caravana migrante en los tres distintos actores colectivos nos lleva a analizar que son los derechos humanos, derecho humano a transitar libremente y como se regula en la normativa migratoria mexicana, esto a fin de entender el contexto de las personas que conforman la caravana migrante.

\section{Concepto de derechos humanos}

Tratar de establecer una definición de derechos humanos es un tema de gran complejidad, pues por principio de cuentas debemos partir del origen de dicho concepto que fue mencionado por primera vez al momento de la promulgación de la Declaración Universal de Derechos Humanos (DUDH), llevada a cabo por la Asamblea General de la Organización de las Naciones Unidas en su Resolución 217 A (III) el día 10 de diciembre de 1948, documento internacional que se compone de dos partes, la primera es un preámbulo que corresponde a la presentación e introducción de dicho documento, en la que incluye las características de los derechos humanos (universales, inalienables, irrenunciables, inextinguibles e inviolables); y la segunda parte comprende a un listado de 30 artículos que corresponden a los diferentes derechos humanos plasmados en esta. Sin embargo, pese a que uno de los objetivos que busca dicho instrumento es el compromiso internacional mediante su adopción en el derecho interno de cada país, el mismo no nos da una definición que nos diga que son los derechos humanos. 'Derechos humanos' no es la expresión adecuada y aquí el consentimiento universal, que se desprende de su utilización generalizada, no es razón para aceptarla como base de un proceso de reflexión que lleve a la comprensión de lo que se quiere identificar [...] En todo caso, tenemos que coexistir con una utilización tan difundida, intentando explicar los límites del uso de este tipo de lenguaje, y sobre todo, tenemos que evitar la definición basada en lo que se dice en el lenguaje natural, sea el punto de partida para justificar otros términos, pretendidamente más sólidos para expresar la idea de 'derechos humanos'. (Peces-Barba, 2004: 21) 
Por lo tanto, la carencia de una definición que nos brinde lo que se debe entender por los derechos humanos ha hecho que exista una aplicación variada sobre este concepto, a tal grado que existen más conceptos como el de los derechos naturales, derechos públicos subjetivos, derechos fundamentales, libertades públicas y derechos morales que tienen su origen a su vez en distintos sistemas jurídicos, y dada la similitud en cuanto a su matiz ideológica que es la búsqueda de la protección del ser humano en contra de cualquier acto abusivo que vaya en contra de este, ha generado precisamente una confusión conceptual entre estos. Lo anterior se puede constatar en múltiples discursos políticos, de activismo en defensa de algún movimiento social y en trabajos de investigación que se enarbolan en la bandera de los derechos humanos para tratar de justificar alguna causa; por ejemplo, Szabo (1984), citado por (Fuentes \& Ortiz, 2012: 161) nos dice lo siguiente sobre los derechos humanos: "los derechos humanos son derechos fundamentales por la propia razón de que existieron antes que el Estado". Esta breve cita nos da a entender que los derechos humanos y los derechos fundamentales se tratan de sinónimos, pero claramente reflejan una clara confusión conceptual entre estos.

En los derechos fundamentales el espíritu y la fuerza, la moral y el Derecho están entrelazados y la separación los mutila, los hace incomprensibles. Los derechos fundamentales son una forma de integrar justicia y fuerza desde la perspectiva del individuo propio de la cultura antropocéntrica del mundo moderno. En el horizonte de la comprensión de los derechos fundamentales, moral y Derecho aparecen conectados por el Poder. Los derechos fundamentales que se originan y se fundan en la moralidad y que desembocan en el Derecho, lo hacen a través del Estado que es el punto de referencia de la realidad jurídica a partir del Tránsito a la Modernidad. (Peces-Barba, 2004: 31)

Contrario a lo que expone Szabo, los derechos fundamentales se encuentran más ligados con el positivismo del derecho: "Como primera instancia son los que designan las facultades o pretensiones garantizadas en virtud de un ordenamiento positivo [...]" (Acuña, 2010: 155), por lo que los derechos fundamentales tienen la particularidad de que deben encontrarse comprendidos dentro de un ordenamiento legal, vigente, general y coercible, de lo contrario carecen de espíritu o aplicación: [...] son, de una parte, condición de posibilidad de los espacios 
públicos democráticos $\mathrm{y}$, de otra, construcciones o elaboraciones intersubjetivas de sujetos autónomos que se reconocen mutuamente libres e iguales en tanto autores de las normas -esto es, autolegisladores- y miembros de una comunidad jurídica. (Durango, 2010: 249)

Por el contrario, los derechos humanos tienen un origen más arraigado con la corriente del derecho natural o iusnaturalismo, la cual pugna por un sentido más amplio y en consecuencia diferente a lo que establece la corriente del derecho natural o iuspositivista, pues mientras que la segunda depende esencialmente de la previa existencia de un ordenamiento legal que comprenda los derechos, la primera nos habla de que un ser humano es acreedor de ciertos derechos por esa razón, ser un ser humano. Para la concepción iusnaturalista, el origen de los derechos humanos no es el derecho positivo, sino el orden jurídico natural. Dicho orden natural, como los derechos que se deducen del mismo, constituyen expresión y participación de una naturaleza humana que es común y universal a todas las personas. (Nogueira, 2003: 37)

En este sentido, la existencia de los derechos humanos no depende de un ordenamiento legal y vigente como ocurre con los derechos fundamentales arraigados con el modelo positivista, pero tampoco podemos afirmar que los derechos humanos se desligan o son contrarios a la corriente del iuspositivismo, pues en la actualidad a fin de garantizar la aplicación de estos se observa en el iuspositivismo la herramienta jurídica para lograrlo, no obstante, resulta necesario recordar la base ideológica de ambos conceptos para evitar caer en la confusión de querer hacer pasar ambos conceptos como si de sinónimos se tratasen.

2. Derecho humano a transitar libremente y como se regula en la normativa migratoria mexicana

Como ya lo vimos anteriormente, no contamos con una definición de lo que debe entenderse por los derechos humanos, así como la existencia de una confusión en su uso conceptual al punto de que se suelen usar como sinónimos con otras derechos que tienen el mismo fin protector hacia el ser humano, por ende, a que 
La caravana migrante centroamericana: pobreza, violencia y miedo bajo

se refería la Asamblea General de las Naciones Unidas cuando contemplo al libre tránsito como un derecho dentro del listado de artículos de la DUDH:

“Artículo 13. 1.- Toda persona tiene derecho a circular libremente y a elegir su lugar de residencia en el territorio de un estado.

2.- Toda persona tiene derecho a salir de cualquier país, incluso del propio, y a regresar a su país. ${ }^{7}$

El texto del artículo en comento contempla dos situaciones de tránsito en sus respectivos apartados que corresponden al derecho a transitar libremente, el primer apartado se refiere a la libre circulación del ser humano dentro del territorio que corresponde al estado del que es originario: "Un derecho es una libertad cuando el titular o sujeto activo tiene derecho a que nadie lo interfiera en el ejercicio del derecho. Es el caso de la libertad de circulación y residencia, de la libertad de opinión." (Nogueira, 2003: 64), mientras que el segundo se refiere a la circulación de cualquier ser humano fuera del territorio que comprende al estado del que es originario, así como a regresar a su terruño. Centra nuestra atención el segundo apartado del artículo 13 de la DUDH, pues sin expresarlo literalmente dispone un deber para estados ajenos al nacional para permitirle el ingreso y circulación a un extranjero por su territorio, entonces que tan cierto es el derecho de libertad de tránsito para los extranjeros.

Otra situación además de la inexistencia de una definición de los derechos humanos que hace difícil de comprenderlos, y en este caso, al derecho a transitar libremente es el hecho de que cada estado en base a su soberanía regula tal derecho, muchas veces en base a la demanda de extranjeros que desean residir de forma temporal o definitiva, situación que se encuentra fuertemente ligada a las causas y consecuencias de la migración irregular que abordamos con antelación. Veamos tal caso dentro del sistema jurídico mexicano, respecto del cual primero debemos abordar su reforma constitucional de fecha 10 de junio de 2011, por medio de la cual se incorporó el término derechos humanos al texto de la

\footnotetext{
${ }^{7}$ Declaración Universal de los Derechos Humanos, Adoptada y proclamada por la Resolución de la Asamblea General 217 A (III) del 10 de diciembre de 1948.
} 
Constitución Política de los Estados Unidos Mexicanos, máximo ordenamiento legal a partir del cual se abre un nuevo paradigma de aplicación e interpretación de las normas comprendidas por el mismo, pues se abandonó el viejo modelo de garantías individuales fuertemente arraigado a la teoría del iuspositivismo, el cual se ceñía solo a lo estrictamente al texto de la norma; por el contrario, con la incorporación de los derechos humanos al texto constitucional ahora se da entrada a una especie de jerarquía normativa compartida entre la propia constitución federal, los derechos humanos y los tratados internacionales que versen sobre estos derechos. Es decir, se deja de observar una jerarquía vertical normativa por una horizontal.

En tal contexto, el derecho humano a transitar libremente ahora se encuentra en un rango jerárquico superior dentro del sistema jurídico mexicano consagrado en el artículo 11 de la constitución federal, y regulado de la siguiente manera: Toda persona tiene derecho para entrar en la República, salir de ella, viajar por su territorio y mudar de residencia, sin necesidad de carta de seguridad, pasaporte, salvoconducto $\mathrm{u}$ otros requisitos semejantes. El ejercicio de este derecho estará subordinado a las facultades de la autoridad judicial, en los casos de responsabilidad criminal o civil, y a las de la autoridad administrativa, por lo que toca a las limitaciones que impongan las leyes sobre emigración, inmigración y salubridad general de la República, o sobre extranjeros perniciosos residentes en el país. ${ }^{8}$

De lo ya transcrito podemos recalcar lo siguiente:

El artículo 11 de la Constitución federal reconoce el libre tránsito como un derecho, tanto de los propios mexicanos como de cualquier extranjero que desee internarse en su territorio;

Establece que para ingresar a territorio mexicano no es necesario presentar carta de seguridad, pasaporte, salvoconducto u otros requisitos semejantes; y

Establece limitantes a este derecho: judiciales, administrativos y legales.

El libre tránsito o la libertad de circulación por territorio mexicano de acuerdo

\footnotetext{
${ }^{8}$ Decreto por el que se reformó el primer párrafo del artículo 11 de la Constitución Política de los Estados Unidos Mexicanos, publicado en el Diario Oficial de la Federación el 15 de Agosto de 2016.
} 
con su Constitución federal es un derecho humano gracias a la denominación que la propia Constitución federal hace en el Capítulo I, de si Título I, sin embargo, establece ciertas excepciones o candados normativos y jurídicos que hacen que este derecho tenga una limitante para extranjeros y no así para los mexicanos, haciendo de este modo una distinción de seres humanos: "Los derechos públicos son los derechos primarios reconocidos sólo a los ciudadanos o nacionales, como es la libertad de circular libremente por el territorio nacional, residir y entrar y salir libremente del mismo; el derecho al trabajo, entre otros." (Nogueira, 2003: 65); Es en este punto donde surge la interrogante sobre si es verdad que lo que regula la Constitución federal mexicana es un derecho humano, pues de acuerdo a la teoría de los mismos al tratarse prerrogativas que buscan la protección de la dignidad del ser humano, no debería ni siquiera hablarse de distinción entre nacional y extranjero, pues ello no es elemento o requisito que reste humanidad a persona alguna, ¿o sí?, más aun, cuando al principio del texto del artículo constitucional en comento dispone que no es necesario para ingresar a territorio mexicano presentar carta de seguridad, pasaporte, salvoconducto $\mathrm{u}$ otros requisitos semejantes, pero casi inmediatamente después, delega la regulación de este derecho a normas secundarias que sí disponen la necesidad de presentación de documentación como requisitos para ingresar a territorio mexicano, los que se encuentran establecidos en el artículo 60 del Reglamento de la Ley General de Migración: Para autorizar la internación de personas extranjeras, la autoridad migratoria, en el filtro de revisión, en caso de duda podrá corroborar los requisitos que a continuación se indican:

I. Pasaporte o documento de identidad y viaje que sea válido conforme al derecho internacional y, en su caso, visa o documento migratorio;

II. Información y datos personales que le sean requeridos;

III. Motivo del viaje;

IV. Lugar de residencia habitual o de procedencia;

V. Domicilio y tiempo de estancia en el territorio nacional;

VI. En su caso, nombre, denominación o razón social y domicilio de la persona física o moral que lo empleará o lo invita; 
VII. Actividades a las que se dedica en su país o lugar de procedencia y las que realizará en el territorio nacional;

VIII. Los medios de subsistencia durante su estancia en el territorio nacional, salvo el caso de las personas extranjeras que porten visa mexicana, y

IX. El transporte que utilizará para efectuar su salida.

En caso de que la autoridad migratoria advierta que la persona extranjera no cumple con los requisitos de ingreso, exista una alerta migratoria, encuentre inconsistencias en la información, o bien, falta de autenticidad o veracidad de los documentos presentados, la persona será enviada a una segunda revisión. La autoridad migratoria realizará la segunda revisión del pasajero y determinará su admisión al territorio nacional o rechazo al lugar de procedencia o a aquél donde sea admisible, debiendo fundar y motivar su resolución. Durante la segunda revisión, la persona extranjera podrá manifestar lo que a su derecho convenga y exhibir los medios de prueba que considere convenientes, mismos que deberán ser valorados y analizados por la autoridad migratoria a efecto de resolver conforme a derecho la internación o rechazo y será informado sobre la posibilidad de comunicarse con su consulado durante el plazo que dure la segunda revisión. En los casos de personas que al momento de solicitar su internación al territorio nacional se ostenten como mexicanos y la autoridad migratoria cuente con los elementos suficientes para presumir la falta de autenticidad de la documentación que exhiban o en los elementos que aporten para acreditar la nacionalidad mexicana, se deberá determinar lo conducente con los elementos que tenga a su alcance. La segunda revisión no podrá exceder de cuatro horas. Igual plazo tendrá la autoridad migratoria para el caso de personas extranjeras sujetas a segunda revisión, mismo que sólo podrá ampliarse a solicitud expresa de la persona extranjera o de su representante consular. En ningún caso el plazo podrá ser mayor a veinticuatro horas. (Reglamento de la Ley de Migración, 2012: art. 60)

Dicho precepto establece que el personal migratorio, previo a permitir el ingreso y tránsito a extranjeros por territorio nacional, deberá activar los filtros de revisión y requerir a las personas que ingresan a México que proporcionen 
documentación e información como el pasaporte, documento de identidad, visa (que se requiere para todo ciudadano que sea originario de la región del TNC) o documento migratorio, información y datos personales que le sean requeridos, motivo del viaje, lugar de residencia habitual o de procedencia, domicilio y tiempo de estancia en el territorio mexicano; o si el motivo de su ingreso es por motivos de trabajo, deberá proporcionar nombre, denominación o razón social y domicilio de la persona física o moral que lo emplea o lo invita, que señale las actividades a las que se dedica en su país o lugar de procedencia y las que realizará en el territorio nacional, mostrar los medios de subsistencia durante su estancia en el territorio nacional salvo el caso de las personas extranjeras que porten visa mexicana, y el transporte que utilizará para efectuar su salida. La finalidad de realizar esas medidas es contar con un control de los extranjeros que ingresan y egresan del territorio nacional, ello básicamente por cuestiones de seguridad.

Sin bien todas estas disposiciones son razonables en el marco de la ley, ellas se encuentran establecidas para una situación completamente diferente a la que se vive con la caravana migrante. La mayor parte de los viajeros en desplazamiento migratorio no cuenta con el mínimo de los requisitos necesarios para un desplazamiento ordenado. El panorama se intensificó cuando nuevas caravanas ingresaron de manera marginal, rompiendo fronteras y restricciones para ingresar a territorio mexicano, lo cual ha sido una constante desde que iniciaron las primeras caravanas migrantes en el mes de octubre de 2018: De octubre del 2018 a abril se han realizado alrededor de seis caravanas de migrantes que tienen como objetivo llegar a Estados Unidos; actualmente en territorio mexicano permanecen más de 5,800 extranjeros en tránsito por diversos estados, principalmente en Chiapas, que es la puerta de ingreso al país... En la recta final del gobierno de Enrique Peña Nieto, se emprendieron cuatro caravanas, mientras que en los primeros meses de la administración de Andrés López Obrador se tiene el registro de al menos dos grandes grupos de migrantes compuestos principalmente por originarios de Guatemala, Honduras, El Salvador, aunque también de ciudadanos africanos... En su calidad de presidente electo, Andrés Manuel López Obrador prometió que a los migrantes extranjeros se les respetarían sus derechos en el paso por territorio mexicano y ofreció otorgarles permisos de trabajo para incorporarse a proyectos 
como el Tren Maya... De acuerdo con el gobierno federal, la política migratoria consta de dos principios: el respeto irrestricto a los derechos humanos y el desarrollo social y económico como base de las dinámicas migratorias... En los primeros tres meses de gobierno de López Obrador, se han deportado a 31,494 extranjeros que entraron de manera ilegal a México. (El Economista, 2019)

Sin duda, se trató de un escenario de gran complejidad para las autoridades mexicanas quienes debían responder a un control de revisión migratoria tomando en cuenta la perspectiva de derecho humanos y a su vez, al verse sobrepasadas ante la demanda y desesperación por el ingreso de cientos de personas, tuvieron que ceder ante el chantaje arancelario del mandatario estadounidense Donald Trump quien condicionó el comercio de México y Estados Unidos a cambio de un control estricto de la frontera sur de México. En este punto podemos observar como se ha hecho una ponderación entre factores políticos regionales y el supuesto derecho a transitar libremente consagrado en la constitución federal: "El procedimiento de ponderación de los bienes debe partir de que los derechos a limitar en su ejercicio y los valores constitucionales o los bienes constitucionales aparecen como contrapuestos." (Nogueira, 2003: 111). Esto nos muestra cómo es que pese al carácter jerárquico que se pretende brindarles a los derechos humanos llega a chocar con los intereses políticos de los estados, poniéndose estos en una balanza donde no siempre los derechos humanos pesan más que dichos intereses: Los límites inmanentes a los derechos fundamentales se averiguan mediante la ponderación de bienes, en la que se analiza el sistema de valores objetivos establecidos por la carta fundamental. De manera tal que si la ley restringe un derecho esencial más allá de lo que obliga un bien jurídico de igual o mayor jerarquía o rango, esta restricción no podría permitirse, siendo inconstitucional. (Idem)

Esta difícil situación de ponderación de derechos humanos se materializa con los mecanismos de vigilancia y control migratorio que han sido reforzados con la Guardia Nacional. Por su parte, los integrantes de las caravanas migrantes se encuentran ante la incertidumbre y el miedo del posible trato que las autoridades mexicanas (de cualquiera de los tres niveles de gobierno, o de los tres poderes) puedan darles, las detenciones, deportaciones, y discriminaciones por parte de 
tanto de las autoridades como de la sociedad, sumando además la violencia perpetrada por parte de grupos criminales organizados en el país.

Se requiere una legislación migratoria que regule la función de la autoridad administrativa competente ya no en aras de una detención migratoria, sino con una perspectiva en donde la detención de las personas extranjeras en situación migratoria no documentada sea considerada como último recurso. Sin una base normativa con perspectiva de derechos humanos, resultará sumamente complejo construir modelos eficaces alternativos a la detención. (CNDH, 2019: 274 y 275)

El panorama no resulta nada alentador para los integrantes de la caravana migrante, pues tal y como lo expone la Comisión Nacional de Derechos Humanos, se enfrentan a la posibilidad de ser víctimas de malos tratamientos por parte de las autoridades migratorias nacionales, que va desde la forma en que son detenidas y su hacinamiento en los centros de control migratorio que pueden atentar en contra de su dignidad como seres humanos, por tal motivo se requiere de un cambio integral de visión respecto al fenómeno de migración internacional que tienen las autoridades migratorias; es decir, la forma en que ven a los migrantes irregulares, y por ende como los tratan, pues tal parece que por su condición se tratasen de delincuentes: La práctica sistemática de la deportación y las formas con las que se induce el retorno asistido requiere sistemas de monitoreo y control (eventualmente disciplinario) de la acción de las fuerzas de orden; así como la institucionalización de protocolos de información sobre el derecho de asilo en el momento de la detención. (Morondo \& Blanco, 2018: 51)

Pues además de lo anterior, los migrantes irregulares corren el riesgo de que su travesía se vuelva un verdadero martirio ante la posible violencia de que puedan ser sujetos, sobre todo al llegar al contexto fronterizo de México con los Estados Unidos: "En el cruce a los Estados Unidos se enfrentarán al paso por el desierto, o la posibilidad de morir ahogados en el río Bravo, se hallan a merced de redes de polleros que los internan en el país de manera clandestina, padecen la criminalización de que son objeto por su ingreso irregular, con el riesgo de caer en redadas o ser detenidos por su fenotipo o por faltas menores." (Vega, 2018: 87). Todo parece indicar que en escenarios como estos hay poca o nula cabida para defensas justas desde una perspectiva de derechos humanos. 


\section{Conclusiones}

Con la promulgación de la DUDH el día 08 de diciembre de 1948 por la Asamblea General de las Naciones Unidas se ha buscado establecer mecanismos por medio de los cuales los estados garanticen los derechos comprendidos en la misma con la finalidad de contar con instrumentos que protejan a todo ser humano sin importar su raza, religión, sexo, orientación, preferencias de todo tipo, de cualquier situación o acción que pueda vulnerar su integridad y dignidad. En tal contexto, no debieran existir limitantes a la hora de hablar de la protección de los derechos humanos, por lo que la condición legal migratoria de cualquier persona no tiene cabida en estas.

México tiene una gran deuda en materia de derechos humanos dentro de los procesos de migración irregular que se suscitan dentro de su territorio. Por un lado, es cierto que México al ser un país soberano cuenta con las facultades para crear leyes por medio de las cuales se regulen actos humanos que se susciten dentro de su sociedad o que afecten a las personas que la conforman, como es el caso del ingreso, tránsito y egreso de extranjeros por su territorio. Si bien, el artículo 11 de la Constitución Federal reconoce el libre tránsito como derecho humano (al igual que el artículo $13 \mathrm{DUDH})$, la Ley de Migración y su reglamento lo hacen más como si se tratase de una prestación de servicios que brinda el estado mexicano a todo extranjero que desee internarse a su territorio, estableciendo para tal motivo una serie de requisitos y gastos que deberán ser cubiertos para tal motivo. Con ello se puede observar que el derecho humano a la libertad de tránsito solo está garantizado para las personas que pueden acceder a las solicitudes impuestas por el gobierno mexicano, excluyendo con ello a quienes no cuenten con esa capacidad económica.

Las disposiciones migratorias mexicanas se encuentran establecidas a partir de requisitos económicos que más que permitir el derecho de libertad de tránsito establecen restricciones al mismo y que ante la gran demanda por ingresar a territorio mexicano por parte principalmente de centroamericanos no hace más que aumentar la problemática dentro de los fenómenos migratorios, en los que la condición legal migratoria de los extranjeros será un factor que garantice no 
solo el derecho humano de transitar libremente, sino además, la garantía de otros derechos humanos como lo son la vida, la salud, trato y seguridad jurídica, integridad personal, ya que quienes no puedan cubrir los requisitos administrativos migratorios en caso de internarse irregularmente a México se verán orillados a vivir en la marginalidad social, tratando de pasar lo más desapercibidos posibles para evitar ser detenidos y deportados volviéndolos un grupo vulnerable para la comisión de actos que atenten en contra de sus derechos humanos.

Así, la condición migratoria que cualquier persona tenga con relación a un país distinto al propio, no puede ser un factor que impida proteger y garantizar los derechos humanos, (en este caso de los migrantes con documentación irregular) puesto que en sentido contrario se atentaría contra la universalidad de los derechos humanos, característica que establece que la protección de estos derechos al ser inherentes al ser humano no pueden estar sujetos a condición alguna para su ejercicio y garantía. Sin embargo, ello queda en letra muerta u olvido no solo por parte de México, sino por una gran cantidad de países dentro de sus regulaciones migratorias, ya que si se hiciera efectiva la característica de universalidad de los derechos humanos, debería existir 'uniformidad'en la regulación migratoria, la cual debería estar encaminada no solo a que estos procesos se lleven de la mano de los derechos humanos, sino de que ese proceso sea reconocido como un auténtico derecho humano.

Es entonces que los fenómenos de migración irregular afrontan la ponderación de derechos; por un lado, la facultad de los países de establecer los procesos de regulación migratoria a partir de su soberanía frente a lo que es el derecho humano de transitar libremente, así como de las garantías por medio de las cuales hacer efectiva la protección de otros derechos humanos. Pero es en estos casos en los cuales debemos hacernos la siguiente pregunta: ¿en el sistema jurídico mexicano existe cabida de ponderación de derechos frente a los derechos humanos?

Si en la actualidad México por medio de su reforma constitucional de 10 de junio de 2011 estableció un nuevo paradigma en materia de derechos humanos por medio de su reconocimiento e incorporación dentro del texto de la Constitución Federal, máximo ordenamiento legal en el país, sumándose a ese reconocimiento los tratados internacionales en materia de derechos humanos los cuales quedan a la par de rango jerárquico que la Constitución en comento. Lo cierto es que el 
derecho de transitar libremente, así como la protección y garantía de derechos humanos dentro de procesos de migración irregular no deberían de estar sujetos a ponderación, dado ese rango jerárquico normativo que ahora se les reconoce en la constitución, por lo cual, nos encontramos frente a una grave contradicción de aplicación normativa, en la que la peor parte se la llevan los migrantes irregulares frente a las actuaciones que como respuesta da el estado mexicano para hacer frente a un fenómeno de migración irregular como el de la caravana migrante.

Es urgente cambiar el diálogo que hemos tenido a nivel nacional e internacional sobre el derecho humano de transitar libremente y en su regulación, se requiere un nuevo consenso de los actores involucrados en los procesos de migración irregular que tengan siempre presente que la libertad de tránsito se trata de un derecho humano y que por lo tanto es un imperativo de garantía de protección no solo de los estados, sino también de las personas que deseen ingresar a un país distinto al suyo.

La normativa como actividad encaminada a regular las conductas humanas desde la implementación de la reforma constitucional en materia de derechos humanos ya no puede hacer un trato diferenciado entre extranjeros y connacionales o entre extranjeros regulares e irregulares, ya que ninguna situación legal regulada puede ir en contra de la condición del ser humano. 


\section{Bibliografía}

Acuña, L. (2010). ¿Qué entendemos por Derechos Humanos y Derechos Fundamentales? Justicia, 151-161.

Arista, L. (27/abril/2019), "Caravanas de migrantes en México", El Economista, Recuperado de: https:/www.eleconomista.com.mx/ politica/Caravanas-de-migrantes-en-Mexico-20190427-0001.html

Alto Comisionado de las Naciones Unidas para los Refugiados. (2017).

Situación del Triangulo Norte de Centroamérica, datos relevantes.

Fecha de consulta: 22/ abril/2019 https://www.acnur.org/fileadmin/ Documentos/BDL/2017/11040.pdf

Casillas, R. (2008). Las rutas de los centroamericanos por México, un ejercicio de caracterización, actores principales y complejidades. Migración y Desarrollo, 157-174.

Centro de Estudios de Guatemala. (2018). Proyecto de Apoyo Técnico Sustantivo para la Promoción e Implementación, de los Estándares Internacionales de Seguridad, Justicia y Derechos Humanos en la Agenda Legislativa de Guatemala. Centro de Estudios de Guatemala. Guatemala: Centro de Estudios de Guatemala.

Centro de Estudios Sociales y de Opinión Pública. (2015). La falta de oportunidades como factor coadyuvante para la integración de jóvenes en el crimen organizado. Congreso de la Unión, Cámara de

Diputados. México, D.F.: Cámara de Diputados, LX Legislatura.

Constitución Política de los Estados Unidos Mexicanos. (08 de Mayo de 2020). Diario Oficial de la Federación. Ciudad de México, México:

Cámara de Diputados del H. Congreso de la Unión.

Comisión Nacional de Derechos Humanos. (2019). Informe especial. Situación de las estaciones migratorias en México, hacia un nuevo modelo alternativo a la detención. Ciudad de México: Comisión Nacional de los Derechos Humanos.

Durango, G. (2010). El concepto de los derechos fundamentales en la teoría habermasiana: de la acción comunicativa a facticidad y validez. Revista de Derecho, 247-276. 
Fuentes, G., \& Ortiz, L. (2012). El migrante centroamericano de paso por México, una revisión a su condición social desde la perspectiva de los derechos humanos. Convergencia revista de ciencias sociales, 157-182.

Grau Crespo, A. (2013). "Situación de empleo joven en Centroamérica" Análisis Comparativo con perspectivas hacia politicas públicas de empleo juvenil. Tegucigalpa, Honduras: Friedrich-Ebert-Stiftung FES (Fundación Friedrich Ebert).

Gómez, J. (2010). La migración internacional: Teorías y enfoques, una mirada actual. Semestre Económico, 81-100.

Hernández Franco, J. A. (2011). Sociología general y Jurídica, México, D.F.: Oxford Univeristy Press.

Instituto Centroamericano de Estudios Fiscales. (2015). Posición ante el Plan de la alianza para la prosperidad del Triángulo Norte. Fecha de consulta: 16/agosto/2019 https://icefi.org/sites/default/files/ posicion_ante_el_plan_de_la_alianza_para_la_prosperidad_del triangulo_norte_ca_03-2015.pdf

Instituto Nacional de Migración. (25 de Octubre de 2019). Países y regiones que requieren visa para viajar a México. Recuperado el 02 de Agosto de 2020, de Vigente a partir del 9 de noviembre de 2012: https:/www.inm.gob.mx/gobmx/word/index.php/paises-requierenvisa-para-mexico/

Instituto Tecnológico Autónomo de México. (2014). Migración centroamericana en tránsito por México hacia Estados Unidos: Diagnóstico y recomendaciones hacia una visión integral, regional $y$ de responsabilidad compartida (Primera ed.). (E. Rodríguez, Ed.) México, D.F.: Instituto Tecnológico Autónomo de México.

Jiménez, E. (2016). La violencia en el Triángulo Norte de Centroamérica: una realidad que genera desplazamiento. Papel Político, 167-196.

Martínez, G., Cobo, S., \& Narváez, J. (2015). Trazando rutas de la migración de tránsito irregular o no documentada por México. Perfiles Latinoamericanos, 127-155. 
Morondo, D., \& Blanco, D. (2018). Estudio sobre la situación de las personas LGTBI del norte de Centroamérica con necesidades de protección internacional en Guatemala y México. Madrid, España: Agencia Española de Cooperación Internacional para el Desarrollo. Nogueira, H. (2003). Teoría y dogmática de los derechos fundamentales. México, D. F., México, D. F., México: Universidad Nacional Autónoma de México.

París, M., Ley, M., \& Peña, J. (2016). Migrantes en México vulnerabilidad y riesgos un estudio teórico para el programa de fortalecimiento institucional "reducir la vulnerabilidad de migrantes en emergencias". Ginebra, Suiza: Organización Internacional para las Migraciones.

Peces-Barba, G. (2004). Lecciones de Derechos Fundamentales. Madrid: Dykinson.

Reglamento de la Ley de Migración. 28 de septiembre de 2012. Diario Oficial de la Federación. México D.F., México: Cámara de Diputados del H. Congreso de la Unión.

Sánchez Soler, Martha, Movimiento Migrante Mesoamericano. ¿Quiénes somos? Fecha de consulta: 09/noviembre/2019 https:// movimientomigrantemesoamericano.org/

Rodríguez, E. (2014). Migración centroamericana en tránsito por México hacia Estados Unidos: Diagnóstico y recomendaciones: Hacia una visión integral, regional y de responsabilidad (Primera ed.). México, D.F.: Instituto Tecnológico Autónomo de México.

Vega Villaseñor, H. (2018). Migración de tránsito y acción humanitaria. Tonalá, Jalisco, México: Universidad de Guadalajara, Centro Universitario de Tonalá.

Willers, S. (2016). Migración y violencia: las experiencias. Sociológica, 163-195.

Cómo citar el artículo: Castellano C, Martínez D, (2021). La caravana migrante centroamericana: pobreza, violencia y miedo bajo el prisma de los derechos humanos. Derecho Global, Estudios sobre Derecho y Justicia, VI (17) pp. 133-165 https://DOI. org/10.32870/dgedj.v6i17.313 